\title{
Public Expenditure on Education and Healthcare in Nigeria: Who Benefits and Why?
}

\author{
Uzochukwu Amakom ${ }^{1}$ \\ ${ }^{1}$ Department of Economics, Nnamdi Azikiwe University, Anambra State, Nigeria \\ Correspondence: Uzochukwu Amakom, Department of Economics, Nnamdi Azikiwe University, Awka, P. M. B \\ 5025, Awka, Anambra State, Nigeria. Tel: 234-803-712-3219. E-mail: uamakom@gmail.com
}

Received: January 5, 2012 Accepted: May 16, 2012 Online Published: June 16, 2012

doi:10.5539/ijbm.v7n12p48

URL: http://dx.doi.org/ijbm.v7n12p48

This Paper is an extraction from a research sponsored by the African Economic Research Consortium (AERC), Nairobi, Kenya.

\begin{abstract}
People routinely expect their government through public policy to reduce poverty and inequality, and public spending is one way a policy maker works towards achieving such important task. Education and healthcare provision have been suggested as key sectors that help every policy maker achieve the above objective. The study evaluated public spending efforts in reducing inequality and poverty at all levels of these two sectors using the Benefit Incidence Analysis (BIA) in Nigeria. Findings from the study suggest that primary education and healthcare were more pro-poor in absolute terms than tertiary education and healthcare. Secondary education and healthcare reveal mixed results, while the findings suggest location bias in benefits from public spending for both education and healthcare. The study findings therefore, imply that subsidising government services can have more positive effect on income distribution if properly done than direct consumption or income transfers.
\end{abstract}

Keywords: public spending, education, healthcare, benefit incidence

\section{Introduction and the Problem}

The incidence of public spending is crucial for efficient targeting which has become increasingly important in the current era of macroeconomic reforms as most governments are under pressure to reduce their total expenditure due to growing deficits. It is also equally important because if not well-targeted, such spending may not be able to achieve its goals; hence, for this challenge to be met policy makers need information on the structure of the sector and it's financing. In the words of Heltberg et al (2003), reduction in poverty and inequality usually requires a combination of well distributed economic growth and increased investment in human capital, especially among the poor. Education and healthcare are two sectors that can help achieve the above and in most cases (Nigeria inclusive) the state is the major service provider. If it is believed that investment in education and healthcare helps to improve the welfare of the poor, then there is a need to look at who is benefiting from such spending for equity reasons. This is necessary because such information helps in digesting every government financial operations looking at the how this can help in achieving the overall goals and of equity and efficiency across sectors, locations as wells as gender.

Nigeria's public expenditure, as an aspect of fiscal policy for nearly four decades, has been based on two goals of helping to stimulate economic growth, and at the same time ensure a fair and equitable distribution of the proceeds of economic growth. This has been the target of all the policy regimes (Note 1). These policy regimes have also recognized the importance and the need to invest in education and healthcare as one way of tackling sustainable reduction in poverty and inequality with the introduction of notable education and healthcare programmes like Universal Primary Education (UPE) in 1975, National Primary healthcare in the 1990s, Family Economic Advancement Programme (FEAP) of 1992, National Commission for Mass Literacy (NCML) in 1997, Universal Basic Education (UBE) Programme in 2000, Immunization Programmes from 1970 to date, Roll Back Malaria (RBM) in 2001, amongst others. In summary, Nigeria's health targets for nearly four decades include: affordable and cost effective basic health services for $90 \%$ of the population, and $100 \%$ routine and special immunization coverage while that of education target has been Education for All (EFA).

Table 1 below presents basic education and healthcare indicators in Nigeria across regions (geopolitical zones). 
Looking at Table 1, doubts emerge as to whether there have been improvements in education and healthcare given the investments in the two sectors over the years. Table 1 also discloses high inequality in health outcomes according to household quintile which improves as household moves from a poorer quintile to a richer one. The Nigerian case shows inequalities by location, with people in the rural areas contributing $65 \%$ to national poverty, while their urban counterparts contribute $35 \%$. This reveals that poverty is more predominant in the rural sector.

Table 1. Basic social and poverty indicators across region and location in Nigeria

\begin{tabular}{|c|c|c|c|c|c|c|}
\hline Regions/Indicators & North-East & North-West & North-Central & South-East & South-West & South-South \\
\hline Literacy Rate & 46.3 & 53.6 & 63.1 & 56.1 & 57.3 & 63.2 \\
\hline Poverty Incidence (\%) & 72.2 & 71.2 & 67.0 & 26.7 & 43.0 & 35.1 \\
\hline Public Medical Access (\%) & 48.4 & 55.3 & 61.1 & 37.1 & 73.1 & 45.9 \\
\hline \multicolumn{7}{|l|}{ Primary Net Enrolment } \\
\hline Male & 43.7 & 42.2 & 72.5 & 81.6 & 82.3 & 76.8 \\
\hline Female & 41.5 & 38.6 & 72.1 & 80.0 & 81.2 & 76.1 \\
\hline \multicolumn{7}{|l|}{ Secondary Net Enrolment } \\
\hline Male & 26.7 & 27.5 & 47.9 & 58.0 & 65.4 & 56.8 \\
\hline Female & 24.7 & 22.5 & 43.8 & 61.4 & 64.3 & 60.9 \\
\hline Infant Mortality rate & 125 & 114 & 103 & 66 & 69 & 120 \\
\hline Under 5 Mortality rate & 260 & 269 & 165 & 103 & 114 & 176 \\
\hline \multicolumn{7}{|c|}{ Total Number of Public schools } \\
\hline Primary & 8,796 & 16,298 & 11,755 & 5,327 & 9,120 & 7,308 \\
\hline Secondary & 1,341 & 3,791 & 3,680 & 2,138 & 3,547 & 4,176 \\
\hline Tertiary & 28 & 31 & 39 & 26 & 49 & 33 \\
\hline \multicolumn{7}{|c|}{ Total Number of Public Health facilities } \\
\hline Primary & 2,127 & 3,763 & 2,887 & 1,196 & 2,336 & 1,964 \\
\hline Secondary & 91 & 100 & 207 & 88 & 193 & 166 \\
\hline Tertiary & 7 & 11 & 9 & 10 & 12 & 10 \\
\hline Percentage of Population & 13.6 & 25.6 & 14.5 & 11.7 & 19.7 & 15.0 \\
\hline Male headed households & 95.6 & 97.5 & 88.3 & 76.2 & 80.0 & 76.6 \\
\hline $\begin{array}{l}\text { Female } \\
\text { households }\end{array}$ & 4.4 & 2.5 & 11.7 & 23.8 & 20.0 & 23.4 \\
\hline Quintiles & 1 & 2 & 3 & 4 & 5 & \\
\hline Infant Mortality rate & 133 & 140 & 110 & 87 & 52 & \\
\hline Under 5 Mortality rates & 257 & 293 & 215 & 179 & 79 & \\
\hline
\end{tabular}

Source: NBS, 2007. Annual Abstract of Statistics

In this respect, empirical evidence on who benefited from spending on healthcare and education provides clear evidence that goes beyond answering the question of level or amount spent but how well they have been targeted across households. Amount spent is necessary for poverty reduction but better targeting is required for reducing inequality.

\section{Study Goal and Objectives}

The goal of the study is to determine how equitable public expenditures are at every level of education and healthcare through the benefits that accrue to different households' quintiles in Nigeria. In other words, the study's main goal is to determine what the distribution pattern of expenditure in education and health has been and ascertain if public expenditures in these sectors have been progressive, regressive or neutral when compared 
to the $45^{0}$ lines and per capita consumption or expenditure known as the Lorenz curve.

Specifically the study is to analyse benefits from public expenditure on education and healthcare at all levels in Nigeria to ascertain if they are:

- Progressive across different household groups (quintiles).

\section{Conceptual Framework and Methodology}

Analysing benefit incidence of public sector spending is the same as testing the performance of fiscal policy towards achieving poverty and inequality reduction. This is necessary in Nigeria because Nigeria in its quest to achieve poverty and inequality reduction is increasingly resorting to spending discretions which has resulted to increase in nominal terms, the amounts of public resources channelled towards social and community services (Note 2) and established social investment funds such as the Universal Basic Education (UBE) fund and the National Health Insurance Scheme (NHIS).

It has also be noticed that the poor most times are not adequately protected from the unpleasant effects of cuts in public expenditure in Nigeria hence when there is a reduction in the price of oil in the international market (Note 3 ), allocations to social sectors will reduce. This situation therefore becomes in conflict with the suggestion of Ravallion (2002) that there is the need for introduction of safety net measures in other to alleviate the harmful incidence impacts.

Based on the above argument the social welfare functions for Nigeria have been conceptualized as a developmental challenge aimed at maximizing a composite good (poverty reduction and economic growth) with fiscal policy (public expenditure) entering as a right-hand side argument. Representing this mathematically, such welfare functions can be defined using the Gini coefficient of inequality $\left(\mathrm{G}_{\mathrm{y}}\right)$ :

$$
G_{y}=\frac{2 \operatorname{cov}[Y, F(y)]}{\bar{y}}
$$

where cov is the covariance

$Y$ is the level of income

$F(y)$ represents the rank of a household in income distribution already normalised

$\bar{y}$ is the income mean

A combination of the income mean and the Gini coefficient will lead to defining the social welfare as:

$$
W=\bar{Y}\left(1-G_{y}\right)
$$

With this, it can be shown that any increase in mean levels of income $\bar{Y}$ accompanied by a reduction in inequality $G_{y}$ improves the social welfare $W$. A look at equation 2 above reveals a clear impact of public spending on social welfare while Sen (1976) and Yitzhaki (1982) have succeeded in empirically establishing the inverse relationships between inequality and social welfare. Equation 2 above which is the identified social welfare function do have a contextual relevance to Nigeria as articulated in the Vision 20: 2020 (Note 4). The country's fiscal policy has tried to contain deficit and also worked towards avoiding practice of deficit monetization. This is expected to help the country in creating and maintaining unwavering macroeconomic environment, needed for sustained economic growth and a boost to average income level $(\bar{Y})$.

It has also been observed that functional expenditure in Nigeria has been rearranged (Note 5) in favour of social services (especially education and healthcare) and physical infrastructures. Similarly, the further fiscal power decentralisation to the state and local governments is expected to improve the efficiency of public sector. If we take an example of government expenditure on a social service like healthcare or education that has been written formally as:

$$
X_{j} \equiv \sum_{i=1}^{3} E_{i j} \frac{S_{i}}{E_{i}} \equiv \sum_{i=1}^{3} \frac{E_{i j}}{E_{i}} S
$$

where $X_{j}$ is the amount of the social service (education or health) subsidy that benefits group $j^{l}(j$ is the socioeconomic group;

$S$ is the government social expenditure (education or healthcare); 
$E$ is the number of people expected to benefit from government spending (the number of public school enrolment for education and number of people that uses the health facility for the health sector); and the subscript $i$ denotes the level of social service (primary, secondary and tertiary hence $i=1$ to 3 ).

The benefit incidence of total education or healthcare attributed to group $j$, for example, is given by the number of primary enrolments from the group (Eij) or the number of users of primary healthcare from the group (Eij) * (Note 6) by the unit cost of a primary school for education or unit cost of providing primary healthcare added to secondary level for education or healthcare * tertiary education or healthcare, etc.

The share of total education or health spending imputed to group $(X j)$ is then given by:

$$
x_{j} \equiv \sum_{i=1}^{3} \frac{E_{i j}}{E_{i}}\left(\frac{S_{i}}{S}\right) \equiv \sum_{i=1}^{3} e_{i j} s_{i}
$$

Equation 4 depends on two major determinants:

- The $\boldsymbol{e}_{\mathrm{ij}}$ 's which represent the shares of the group in total service use (enrolments in education and number of users of healthcare facilities). These reflect household behaviour.

- The $\mathbf{s}_{\mathrm{i}}$ which is the shares of public spending across the different types of service, reflecting government behaviour.

Equation 4 looked at only one unit of spending for each level of service (education and healthcare). Given variations in poverty and inequality across locations (urban and rural), the study looked at benefit by location. This was justified by the fact that in Nigeria social spending differs across geopolitical location. In order to achieve that, equation (4) above became:

$$
x_{j} \equiv \sum_{k=1}^{n} \sum_{i=1}^{3} \frac{E_{i j k}}{E_{i}}\left(\frac{S_{i k}}{S}\right) \equiv \sum_{k=1}^{n} \sum_{i=1}^{3} e_{i j k} s_{i k}
$$

Where: $i$ 's stand for levels of education or health

$j$ 's stand for the quintiles

$k$ 's stand for location and gender specified in the unit cost estimates.

To be able to carry out a benefit incidence analysis therefore, data on costs of service provision must be pooled with client information to assess how benefits are distributed among the various socioeconomic groups (quintiles). The study adopted the following steps:

1) Identification of households that benefited from public services (education and healthcare).

2) The ranking all recipients and non recipients households by level of welfare (quintiles) using the total household consumption per capita (Note 7).

3) Aggregating individuals ranked according to welfare measures into group of equal size, it was easy to define the population into five quintiles.

4) Placing a value on services received.

5) Obtaining the average unit cost of providing a public service by dividing government spending on the service (net of any cost-recovery fees and out-of-pocket expenses by the users) by the total number of users of the service.

6) Defining the average benefit from government spending on a service as the average unit cost of providing the service, this is derived from the previous step.

7) Showing the cumulative distribution of total consumption vis a vis cumulative participation in public education or healthcare services through graphs across quintiles.

8) Conducting a test to ascertain statistical significance of differences among the concentration curves known as welfare dominance tests.

BIA has been applied by some studies based on some standard assumptions but it has its limitations. Despite its limitations, it is generally believed that the expenditure-based incidence approach can provide a useful first look at the allocation of government expenditure among households. 


\section{Procedure of Testing for Differences in Concentration Curves (Dominance Tests)}

Several approaches have been applied by various authors in testing for differences in concentration curves or dominance tests depending on the interest of analyst. If testing concentration curve(s) dominance against the Lorenz curve of expenditure or against another concentration curve estimated from the same sample is the interest, then the differences between curves ordinates must be computed which is ordinarily known as the standard error. It must be noted that when this approach is used there are bound to be complications owing to the fact that the curves are dependent in such cases. Bishop et al. (1994) and Davidson and Duclos (1997) have provided an appropriate variance-covariance matrix which allows for dependence between curves and this have been seen to overcome the dependent problem of the curves. The duo (Davidson and Duclos (1997)) thus derived an estimator which is a distribution-free standard error for the difference between two concentration curves that may be dependent. Such estimator was used to establish a confidence interval around the estimated concentration curves and then tested for significant differences between them with the null hypothesis that the ordinates of two concentration curves are equal at each of 19 evenly spaced abscissa. According to Howes (1996), the null hypothesis of equality will be rejected if all 19 ordinate pairs are significantly different.

Dominance tests in this study followed the above as applied by Sahn and Younger $(1999 ; 2000)$ and O'Donnell et al. (2007), but in addition to accounting for the possible dependence between concentration curves, the current study used the covariance matrix for the ordinates estimates which was also used by Sahn and Younger (1999).

\section{Data and Sources}

The survey data for the study was primarily drawn from the NLSS 2003/2004, a welfare monitoring survey collected by the NBS in collaboration with the European Union and the World Bank. The data has 19,158 households with complete information out of the 22,000 households in the sample. These households comprised both rural and urban households. Broad issues included in the survey range from access to education, healthcare services, and housing status to possession of assets and other selected living standard indicators. Information was also collected on individual basis for education and healthcare issues.

The following data from secondary sources were helpful in this study:

- Actual revenue and expenditures on education and healthcare across local government, states and the federal level for the year 2004. These set of data were sourced from the Central Bank of Nigeria (CBN), respective states Auditor Generals reports for actual spending on education and healthcare in the 36 states, including the FCT. These reports were already submitted to the African Institute for Applied Economics (AIAE), Enugu, Nigeria. The institution coordinated the State Economic Empowerment and Development Strategy (SEEDS) benchmarking exercise for all states hence has access to all the state finances and expenditures except that of Ogun state in the South-West region which the author sourced directly. The federal component was sourced from the Federal Ministry of Finance, Abuja, Nigeria

- Enrolment rates for every level of education which was sourced from the National Bureau of Statistics (NBS), Federal Ministry of Education as well as the respective states Universal Basic Education Commission (UBEC), Post-Primary School Management Board (PPSMB), National Commission for Colleges of Education (NCCoE), National Board for Technical Education (NBTE), and the Nigerian University Commission (NUC).

\section{Results, Findings and Discussion}

The study analysed benefits across household groups, regions, states and location using the traditional BIA technique as reflected in the study's methodology. The study also graphed concentration curves that show the cumulative distribution of total consumption, plotted against cumulative participation in public education and healthcare services. Concentration curves were applied to test the progressivity, regressivity or neutrality of public expenditure on education and healthcare across household groups by federal spending, states, regions, location and gender. The results of the traditional BIA are presented in Tables 2 and 3 while concentration curves across household groups and by gender are presented in Figures 1-3.

\subsection{Usage of Public Education and Healthcare Facilities across Quintiles and Location}

Benefiting from a facility can only be possible when a household uses such facility: the study analysed the usage of all levels of public and private education and healthcare facilities by household groups (quintiles) and also across location to ascertain who uses and who does not use. Table 2 shows the result of the analysis. 
Table 2. Usage of Education and Healthcare Facilities by Quintiles, type (public/private) \& location

\begin{tabular}{|c|c|c|c|c|c|c|c|c|c|c|c|}
\hline \multirow{2}{*}{$\begin{array}{l}\text { Quintiles } \\
\text { Education }\end{array}$} & \multicolumn{2}{|c|}{1} & \multicolumn{2}{|c|}{2} & \multicolumn{2}{|l|}{3} & \multicolumn{2}{|c|}{4} & \multicolumn{2}{|c|}{5} & \multirow[b]{2}{*}{ No of Households } \\
\hline & Pub & Priv & Pub & Priv. & Pub. & Priv. & Pub. & Priv & Pub & Priv. & \\
\hline Primary & 76.8 & 13.2 & 63.1 & 26.9 & 64.9 & 31.1 & 28.0 & 62.0 & 14.4 & 82.6 & 16,991 \\
\hline Secondary & 55.0 & 15.0 & 53.8 & 38.2 & 40.0 & 50.0 & 36.4 & 60.6 & 30.5 & 67.5 & 17,018 \\
\hline Tertiary & 5.6 & 0.4 & 7.0 & 1.4 & 30.5 & 8.5 & 69.3 & 10.7 & 78.0 & 12.0 & 17,030 \\
\hline Quintiles & & 1 & & & 3 & & & 4 & & & \\
\hline Healthcare & Pub & Priv & Pub & Priv. & Pub. & Priv. & Pub. & Priv & Pub & Priv. & No of Households \\
\hline Primary & 58.9 & 31.1 & 49.4 & 50.6 & 40.8 & 59.2 & 34.6 & 65.4 & 29.9 & 70.1 & 16,991 \\
\hline Secondary & 39.7 & 30.3 & 38.8 & 33.2 & 52.4 & 41.6 & 53.4 & 42.6 & 54.8 & 43.2 & 17,018 \\
\hline Tertiary & 8.3 & --- & 12.8 & --- & 19.8 & --- & 24.3 & --- & 34.8 & --- & 17,030 \\
\hline Education & Urb. & Rur. & Total & & Health & Urb. & Rur. & Total & & & \\
\hline Primary & 47.8 & 52.2 & 100 & & Primary & 39.1 & 60.9 & 100 & & & \\
\hline Secondary & 56.3 & 43.7 & 100 & & Secondary & 47.3 & 52.7 & 100 & & & \\
\hline Tertiary & 62.2 & 37.8 & 100 & & Tertiary & 73.7 & 26.3 & 100 & & & \\
\hline
\end{tabular}

Source: Author's Computation

The results in Table 2 show that more than $70 \%$ and $58 \%$ of households in the first quintile (the poorest households) make use of public primary education and healthcare facilities, respectively, while only $14 \%$ and $29 \%$ of household in the fifth quintile (the richest households) are using the same facilities. It also shows that over $80 \%$ and $70 \%$, respectively, of household in the fifth quintile (the richest households) patronize private primary schools and healthcare centres as against $13 \%$ and $31 \%$, respectively, from the first quintile (the poorest households). Apart from the public and private educational and healthcare facilities, there also exist religious, industrial and other education and healthcare facilities. Such education and healthcare facilities make up for the shortfall from $100 \%$ in the addition of public and private facilities across quintiles.

Another striking evidence from Table 2, is that, usage of public education and healthcare facilities by poorer households (Quintiles 1-3) decreases as the level of education or healthcare increases while usage of public education and healthcare facilities by richer households (Quintiles 4-5) increases with increase in the level of education and healthcare. This, in effect, may imply that usage of higher levels of public education and healthcare facilities depends on how rich every household is.

Generally, the patronage of private tertiary education facilities was still low across household groups (quintiles) which can be explained by the fact that these facilities were, not only fewer in number, but also have very low capacity and limited number of departments and faculties in accepting students during the time of the survey (2005/2006).

Similarly, the lower part of the table presents usage of education and healthcare facilities by location which suggest that rural households use more of the primary education and healthcare facilities than their urban counterparts. The usage of public secondary and tertiary education facilities as well as tertiary healthcare facilities favour urban households' more than rural households. Further enquiry (not reported) also revealed that over $83 \%$ of households visit professional healthcare providers (doctors, nurses, midwife, pharmacists and dentists) during illness as against $8.24 \%$ and $8.03 \%$, respectively, which consult traditional healer and other sources including sorcerers.

\subsection{Benefit Incidence across Household Groups}

The study used data on expenditure of education and healthcare from the three tiers (federal, state and local) of government in conjunction with the survey data in analysing the average benefit incidence from education and healthcare in Nigeria by levels across household groups (quintiles). The results are presented in Table 3. 
Table 3. Average benefit incidence by quintile per social service (

\begin{tabular}{|c|c|c|c|c|c|}
\hline Education & & & & & \\
\hline Quintiles & 1 & 2 & 3 & 4 & 5 \\
\hline Primary & 3,707 & 3,465 & 2,925 & 2,413 & 2,095 \\
\hline Secondary & 3,806 & 3,856 & 4,020 & 3,804 & 3,789 \\
\hline Tertiary & 8,585 & 9,159 & 10,249 & 11,263 & 11,525 \\
\hline \multicolumn{6}{|l|}{ Health } \\
\hline Quintiles & 1 & 2 & 3 & 4 & 5 \\
\hline Primary & 2,795 & 2,728 & 2,718 & 2,352 & 2,188 \\
\hline Secondary & 2,291 & 2,541 & 3,137 & 3,240 & 3,672 \\
\hline Tertiary & 3,133 & 3,512 & 4,071 & 4,361 & 5,055 \\
\hline
\end{tabular}

Source: Author's Computation

The results in Table 3 suggest that benefit incidence was absolutely progressive for primary education and healthcare, progressive for secondary education and regressive for secondary healthcare as well as tertiary education and healthcare (Note 8). These results suggest that poorer household benefited more from government spending in primary education and primary healthcare hence it may not be out of place from such findings to say that primary education and primary healthcare were well targeted. It is also noteworthy that the absolute progressivity of primary education and primary healthcare as portrayed by the result says nothing about quality or standard of services provided just as it fails to capture anything about households' choices. It is possible that richer households may not have benefited much from public primary education because they consider the quality/standard of services very low hence resorting to private schools and healthcare centres for a better background and attention to their wards rather than better targeting. A look at Table 2 shows that only $6.9 \%$ and $10.9 \%$ of the richest quintiles make use of public primary schools and public primary healthcare centres. This may imply that over $85 \%$ of households in the richest quintile may have preferred private primary schools and healthcare centres.

Apart from the quality issue, evidence from the UBEC shows that private primary schools are scanty in the rural areas of the country with about $14 \%$ of the total as against $86 \%$ found in the urban areas. They also pay high tuition and other hidden fees. Such situations are expected to limit the choice of households in sending their children to private schools. This was corroborated by the location result in Table 2 which reveals that usage of public primary schools by rural households was higher than urban households. This may also be the case for primary healthcare because since 2004, most donor interventions ranging from immunization and preventive Medicare are classified under the primary healthcare in Nigeria. These interventions and other healthcare programmes have been targeted to the rural area. Donor intervention programmes though very small compared with total government spending, have also been channelled through the respective levels of government. Also, it is noteworthy that most primary healthcare centres (more than 60\%) are located in the rural area and urban slums. On the other hand, the number of private primary healthcare facilities in most states with high literacy level and states with higher urban concentration are higher than the public primary healthcare outfits. They are more concentrated in the urban with better service quality hence may have lured the urban richer households towards the private healthcare facilities.

The findings that primary education and healthcare spending were progressive in Nigeria have been found by some other studies that dealt on developing countries such as Van de Walle and Nead (1995) for thirteen developing countries; Demery (1996) and the World Bank (1995b) for Ghana and Bulgaria; Rannan-Eliya et al. (2001) for Sri Lanka; Yuki (2003) for Yemen; Heltberg et al. (2001; 2003) for Mozambique where public service provision were found to be more equal than in many other African countries with the exception of the upper secondary and university education, amongst others.

Conversely, the finding of regressivity of spending from Table 4.2 for secondary and tertiary education and healthcare have corroborated findings of other studies from developing countries such as Castro-Leal et al (1999) for seven Sub-Saharan African countries; Ajay et al. (2000) for India and its principal states; Sahn \& Younger (2000) for eight Sub-Saharan African countries; Rannan-Eliya et al. (2001) for Bangladesh; Foster et al. (2002) for Ghana, Malawi, Mozambique, Tanzania and Uganda. Specifically, Sabir (2002) in a study on Pakistan found that government subsidies directed towards higher education either general education or professional education, were poorly targeted to low-income households or indeed favoured those who were better off. 


\subsection{Benefit Incidence by Location}

Table 4 presents the average incidence of benefit by location (urban and rural) for education and healthcare in Nigeria. The results reveal that, rural residents benefited more than the urban residents in both public primary education and healthcare, while the urban residents benefited more from secondary education as well as tertiary education and healthcare. The gap between incidences of benefit for location was felt more in tertiary education and healthcare.

Table 4. Average benefit by location per social service ( $¥)$

\begin{tabular}{lcccc}
\hline \multicolumn{2}{c}{ Education } & \multicolumn{3}{c}{ Health } \\
\hline & Urban & Rural & Urban & Rural \\
Primary & 4,053 & 4,079 & 3,806 & 3,862 \\
Secondary & 6,055 & 5,509 & 4,645 & 4,283 \\
Tertiary & 18,213 & 12,256 & 7,820 & 4,258 \\
\hline
\end{tabular}

Source: Author's Computation

The higher benefit for tertiary education and healthcare by urban residents has been found in many studies and according to Demery (2000) spending on tertiary health facilities (teaching hospitals for example) will not benefit the population at large, as such facilities are used mostly by better off urban residents. This may be true in Nigeria where more than $60 \%$ of public secondary and tertiary education, as well as healthcare facilities, are cited in the urban areas. It should also be noted that, education and healthcare services typically attract higher subsidies in urban than in rural areas. It has also been observed in Nigeria that, education and healthcare services, generally, are often better financed in capital cities than in other urban areas. These variations in unit subsidies may have led to inequalities in the distribution of benefits across location in Nigeria.

\subsection{Tests and Discussions of Differences in Concentration Curves (Dominance Tests)}

Concentration curves used for dominance tests in this study are presented in Figures 1-3 for levels of education and healthcare by household groups in Nigeria. Based on the results in comparison to the 45-degreeline, the t-tests for the differences between ordinates of two concentration curves at 19 abscissa as interpreted and presented in Table 5 above, revealed that with the exception of primary education service no service(s) level was absolutely progressive for national spending. This finding corroborates the finding by Sahn and Younger (2000) for seven African countries, namely, Ghana, South Africa, Guinea, Ivory Coast, Madagascar, Tanzania and Uganda. Based on the same results, the study found tertiary education and tertiary healthcare for national as statistically dominating services or services where the poorer households receive less benefit in per capita terms than households at the upper end of the expenditure distribution. Also, the study found statistically significant crossings for primary healthcare for federal concentration curves as well as secondary education and secondary healthcare concentration curves.

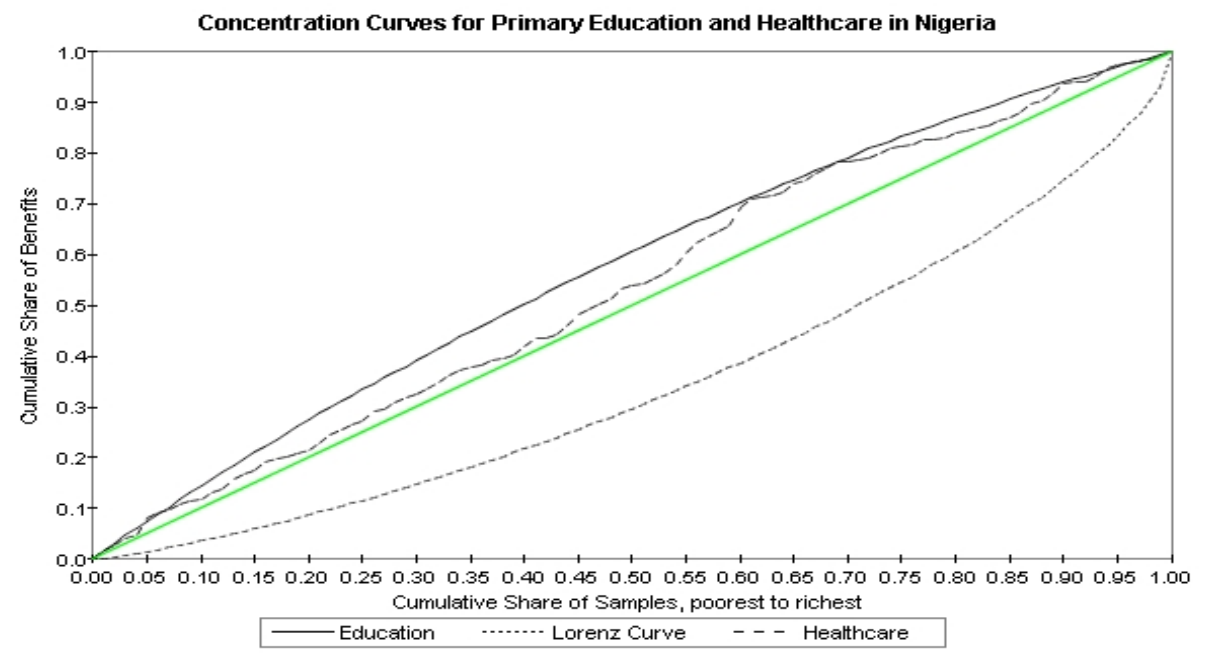

Figure 1. Concentration curves for primary education and healthcare in Nigeria 


\section{Concentration Curves for Secondary Education and Healthcare in Nigeria}



Figure 2. Concentration curves for secondary education and healthcare in Nigeria



Figure 3. Concentration curves for tertiary education and healthcare in Nigeria

Comparison between the Lorenz curve for household expenditure and various categories of social services revealed dominance of social services such as primary healthcare for national concentration curves for primary healthcare. Such findings indicate that, such services were progressive hence the study can reject the null hypothesis of non-dominance between public primary healthcare and federal Lorenz curve. These findings show that, public primary healthcare was more progressive than the distribution of expenditure hence can be adjudged progressive.

Based on the foregoing statistically insignificant progressivity for all levels (except for primary education and healthcare) and across all quintiles, the study therefore cannot reject the null hypothesis that public expenditure on education and healthcare in Nigeria at all levels across households groups were not progressive. The dominance test corroborated with results of the traditional BIA for public spending on education and healthcare at all levels across households groups. 
Table 5. Dominance results for social services (education and healthcare) relative to the Lorenz curve and the 45-degrees line in Nigeria

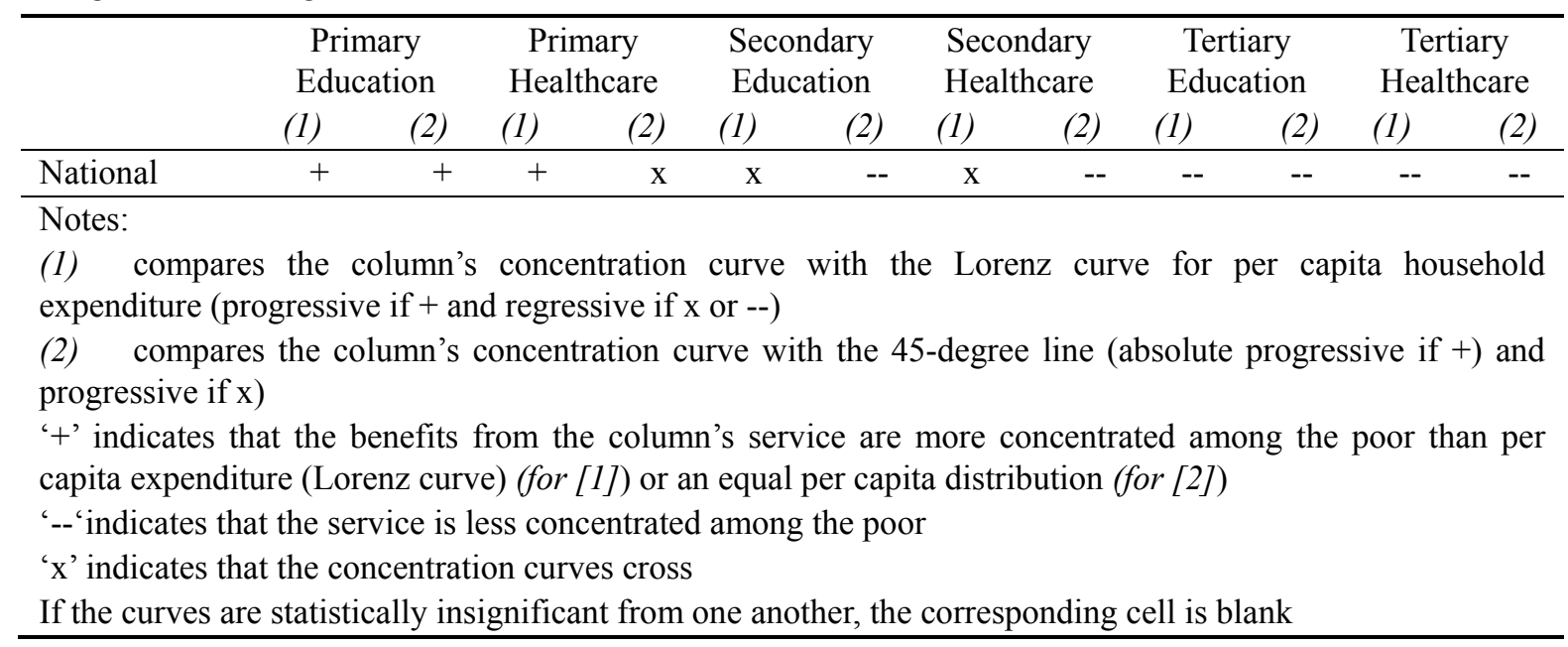

Source: Author's Computation

\section{Discussion of Findings and Conclusion}

The major findings of the study revealed an absolute progressivity for primary education in Nigeria, progressivity for primary healthcare while tertiary education and healthcare were regressive from the federal, regional and state public spending. The finding of absolute progressivity for primary education should be taken with a pinch of salt because benefit incidence says nothing about the standard/quality of public primary education in Nigeria as well as coverage. Descriptive statistics presented in Table 1.2 show the spread of its usage, which suggested that the poor may have benefited more because they use the facilities more. For standard, the average teacher-pupil ratio in Nigeria public primary schools in 2007 was well above 1:40 as against 1:35 as stipulated in the county's educational policy. Available statistics from the National Bureau of Statistics (NBS) showed that teacher-pupil ratio in basic education fell from 7.1\% in 1993 to 5.9\% in 2005 .

In terms of access and coverage, available statistics in 2009 suggested that Nigeria is one of the 15 countries with the highest number of illiterates and one of the top five countries of the developing world that will not achieve any meaningful Education For All (EFA) goals in 2020, let alone 2015. This is because only 22.1million out of 42.1million Nigerian children are in primary schools; only 10.4million out of 33.9 million of those eligible for secondary education are attending; only $25 \%$ of those who sat for Senior Secondary Certificate Examination (SSCE) from 2000 to 2006 passed with credits in Mathematics and English Language, while only 19.5\% out of 1.5 million Nigerians seeking for admission to tertiary education, got admitted (Ikechukwu, 2006). It is expected that most of these children outside the educational system belong to the poorer households. These children are not captured in any statistics and are not known to be part of the nation's calculation when deliberating on investment in capacity issues. They are not in any vocational institutions, trade centres, or skills giving activities planned and delivered by the government as a deliberate policy. The implication, therefore, is that more than $30 \%$ of children who ought to be in primary, secondary or tertiary schools are nowhere nearer to the school environment.

On the healthcare front, the finding that only primary healthcare shows dominance with the Lorenz curve does not mean that primary healthcare system is perfect. Healthcare outcomes in the country remain scary with maternal mortality rate in 2007 estimated at 800 per 100,000 live births (UNDP 2007) and was rated one of the highest in the world. Infant and under-five mortality differ across location ( 81 for urban and 121 for rural) for every 1,000 live births while under-five mortality rate was 243 for rural and 153 for urban for every 10,000 with a life expectancy of 54 years in 2007 (NBS 2008). In summary, health issue in Nigeria is one of the worst.

The regressivity of tertiary education and healthcare spending in Nigeria need an urgent and comprehensive review for the two social service levels. Tertiary level of education and healthcare are known to be out of the reach of the poor in Nigeria and some other developing countries. In tertiary education, apart from the number of such facilities, they also have the problem of capacity in terms of numbers to admit, number of lecturers, standards of facilities and other indicators in education. Similarly, tertiary healthcare facilities suffer from number of beds, number of medical practitioners and equipment as well as under-funding. The two facilities 
have suffered from several and constant industrial actions due to underfunding led agitations by workers which have very high cost to the economy. The NUC estimated the country's financial loss due to 2003 industrial action by the Academic Staff Union of Universities (ASUU) at N83.3 billion or US $\$ 0.72$ billion and US $\$ 1.06$ billion in 2009. For the five months in the two years when the university system were shut down, the nation lost the estimated amount.

It is a general believe that public expenditure can help government achieve the goal of poverty reduction as well as reduction in inequality when the policy setting is right. The present situation in Nigeria may be at variance with right policy setting because it abhors openness in the public expenditure process and most especially in expenditure management including other issues like transparency, participation of stakeholders and accountability. According to Filmer et al. (1998), simply spending money on the provision of a service, without attending to the efficiency with which that spending generates services and to the impact on the intended beneficiaries, is not what is recommended. Nigeria's public spending process should be based on the needs and preferences of the population as well as a sound understanding of the effects of public spending hence making the process a joint venture between the government and the people.

The current study findings have shown that subsidising government services can have more positive effect on income distribution if properly done than direct consumption or income transfers. This further buttress the argument made by Heltberg, Simler and Tarp (2001) that benefit incidence may give some measures of targeting efficiency, but the basis for such targeting does not go beyond the objectives of current income redistribution.

In conclusion therefore, it is noteworthy that benefit incidence analysis does not essentially measure the actual benefits households or individuals receive through public spending but this according to Heltberg, Simler and Tarp (2001) is termed benefit incidence in other to differentiate it from expenditure incidence. Perhaps a better term according to Heltberg, Simler and Tarp (2001) to describe the technique may be beneficiary incidence to avoid the suggestion of measuring true benefits. The aim of the analysis simply suggests that spending is imputed to the beneficiaries.

\section{References}

Ajay, M., J. Singh., \& F. Afridi. (2000). Who Benefits from Public Health Spending in India? Results of a Benefit-Incidence Analysis for India. Washington, D.C: The World Bank.

Bishop, J. A., Chow, K. V., \& Formby, J. P. (1994). Testing for marginal changes in income distributions with Lorenz and concentration curves. International Economic Review, 35(2), 479-88. http://dx.doi.org/10.2307/2527065

Demery, L. (1996). Gender and Public Social Spending: Disaggregating Benefit Incidence. Poverty and Social Policy Department, The World Bank (unprocessed).

Davidson, R., \& Duclos, J. Y. (1997). Statistical inference for the measurement of the incidence of taxes and transfers. Econometrica, 65(6), 1453-65. http://dx.doi.org/10.2307/2171744

Demery, L., Dayton, J., \& Mehra, K. (1996). The incidence of social spending in Ivory Coast, 1986-95. Washington, D.C.: The World Bank.

Demery, L. (2000). Benefit incidence: A practitioners guide. Washington, D.C.: The World Bank.

Filmer, D., Hammer, J., \& Pritchett, L. (1998). Health Policy in Poor Countries: Weak Links in the Chain. World Bank Policy Research Working Paper Number 1874, January.

Foster, M., F. Adrian., F. Naschold., \& T. Conway. (2002). How, when and why does poverty get budget priority: Poverty reduction strategy and public expenditure in five African countries. Working Paper No. 168. Overseas Development Institute, London.

Heltberg, R., Simler K., \& Tarp F. (2001). Public Spending and Poverty in Mozambique. UNU/WIDER project on New Fiscal Policies for Growth and Poverty Reduction.

Heltberg, R., Simler K., \& Tarp F. (2003). Public Spending and Poverty in Mozambique. FCND Discussion Paper No. 167. Food Consumption and Nutrition Division, International Food Policy Research Institute, Washington, D.C.

Howes, S. (1996). A new test for inferring dominance from sample data. Washington, D.C.: World Bank.

Howes, S. (1996b). The Influence of Aggregation on the Ordering of Distributions. JSTOR Economica, 63(250), 253-73. http://dx.doi.org/10.2307/2554762

NBS. (2008). Annual Abstract of Statistics. Abuja, National Bureau of Statistics, Federal Republic of Nigeria. 
O’Donnell, O., E. van Doorslaer., R. P. Rannan-Eliya.,...Y. Zhao. (2007). The Incidence of Public Spending on Health Care: Comparative Evidence from Asia. World Bank Economic Review, 21(1), 93-123. http://dx.doi.org/10.1093/wber/lhl009

Rannan-Eliya, R., Badri, P., Killingworth, J., \& Somanathan. A. (2001). Equity in Financing and Delivery of Health Services in Bangladesh, Nepal and Sri Lanka. Washington, D.C.: The World Bank.

Ravallion, M. (2002). Who is Protected? On the Incidence of Fiscal Adjustment, Washington D.C. The World Bank.

Sabir, M. (2002). Gender and Public Spending on Education in Pakistan: A Case Study of Disaggregated Benefit Incidence. The Pakistan Development Review, 41(4), 477-493.

Sahn, D. E., \& Younger S. D. (1999). Dominance testing of social expenditures and taxes in Africa. IMF Working Paper No. 99/172, Washington D.C.

Sahn, D., \& Younger S. (2000). Expenditure incidence in Africa: Microeconomic evidence. Fiscal Studies, 21(3), 329-48. http://dx.doi.org/10.1111/j.1475-5890.2000.tb00027.x

Sen, A. (1976). Real National Income. Review of Economics Studies, 43(1), 19-39. http://dx.doi.org/10.2307/2296597

The World Bank. (1995b). Ghana: Poverty Past, Present and Future. West Central Africa Department, Report No. 14504-GH, Washington D.C.

The World Bank. (2002). World Development Indicators 2002.

UNDP. (2007). Human Development Report 2007: Fighting Climate Change: Human Solidarity in a Divided World. New York, United Nations Development Programme

Van de Walle, D., \& Nead K. (1995). Public Spending and the Poor: Theory and Evidence. Baltimore and London: The Johns Hopkins University Press for the World Bank.

Van de Walle, D. (1995). The Distribution of Subsidies through public Health Services in Indonesia, 1978-87. Chapter 9 in van de Walle and Nead (1995).

Yitzhaki, S. (1982). Relative Deprivation and Economic Welfare. European Economic Review, 17(1), 99-113. http://dx.doi.org/10.1016/0014-2921(82)90045-9

\section{Notes}

Note 1. Notable policy regimes include the Rolling Plan (1974-1979), the Austerity Measures (1981-1984), the Structural Adjustment Programme (SAP) of 1985-1992, Vision 2010 (1992-1998), Obasanjo Economic Direction (1999-2003), the National Economic Empowerment and Development Strategy (NEEDS) of 2003-2007 and the current Yar'Adua Seven Point Agenda (2007-2011).

Note 2. The Federal Government of Nigeria made available about one billion dollar debt relief. This amount has been channelled to education, health and other MDG sectors annually starting from 2006 as part of the benefits of the debt relief granted Nigeria.

Note 3. A notable shock in Nigeria comes from her overdependence in oil revenue.

Note 4. Vision 20:2020 is Nigeria's road map for development for the period 2009-2020.

Note 5. A telling indicator is the annual channelling of over N100 billion (US\$1 billion) debt relief to key sectors known as MDG sectors since the debt relief of 2006.

Note 6. Multiplied.

Note 7. Total consumption here is the sum of food and non-food consumption expenditures, using standard definitions (see, for example, The World Bank 2000). Food consumption includes all items consumed by the household (from purchase, own production, wages in kind, or transfers). Non-food consumption includes all non-food items, such as clothing, house rents, cooking fuel, transport, education and others as well as imputed values for rents if the household lives in owner-occupied housing, and imputed use values of household durable goods.

Note 8 . The result was further subjected to dominance tests and only primary education passed the absolute progressive test. 